\title{
Degradation of polyethylene by Penicillium simplicissimum isolated from local dumpsite of Shivamogga district
}

\author{
H. V. Sowmya $\cdot$ Ramalingappa $\cdot$ M. Krishnappa $\cdot$ B. Thippeswamy
}

Received: 29 January 2014/Accepted: 8 August 2014/Published online: 29 August 2014

(C) Springer Science+Business Media Dordrecht 2014

\begin{abstract}
Penicillium simplicissimum was isolated from a local dumpsite of Shivamogga district for use in the biodegradation of polyethylene. Degradation was carried out using autoclaved, UV-treated and surface-sterilized polyethylene. Degradation was monitored by observing weight loss and changes in physical structure by scanning electron microscopy, Fourier transform infrared spectroscopy and nuclear magnetic resonance spectroscopy. $P$. simplicissimum was able to degrade treated polyethylene (38\%) more efficiently than autoclaved (16\%) and surface-sterilized polyethylene (7.7 \%). Enzymes responsible for polyethylene degradation were screened from $P$. simplicissimum. Enzymes were identified as laccase and manganese peroxidase. These enzymes were produced in large amount, enzyme activity was calculated using spectrophotometric method, and crude extraction of enzymes was carried out. Molecular weight of laccase was determined as $66 \mathrm{kDa}$ and that of manganese peroxidase was $60 \mathrm{kDa}$. Capacity of crude enzymes to degrade polyethylene was also determined. By observing these results, we can conclude that $P$. simplicissimum may act as solution for the problem caused by polyethylene in nature.
\end{abstract}

Keywords Polyethylene $\cdot$ Penicillium simplicissimum - Laccase $\cdot$ Manganese peroxidase - Scanning electron microscopy - Fourier transform infrared spectroscopy Nuclear magnetic resonance spectroscopy $\cdot$ Biodegradation

H. V. Sowmya $\cdot$ B. Thippeswamy

Department of P.G. Studies and Research in Microbiology, Davanagere University, Shivagangotri, Tholuhunse, Davanagere, Karnataka, India

Ramalingappa (ه)

Department of P.G. Studies and Research in Microbiology, Bioscience Complex, Kuvempu University, Jnanasahyadri, Shankaraghatta, Shivamogga (Dist.,) 577 451, Karnataka, India e-mail: ramalingappa.88@gmail.com

M. Krishnappa

Department of P.G. Studies and Research in Applied Botany, Bioscience complex, Jnanasahyadri, Kuvempu University, Shankaraghatta, Shivamogga (Dist.,) 577 451, India 


\section{Introduction}

Polyethylene, a stable and common commercial plastic, presents a costly and persistent environmental problem. Polyethylene or polythene is the most common plastic. The annual global production is approximately 80 million metric tons (www.wikepedia.org). During the past three decades, plastic materials are increasingly used in transportation, food, clothing, shelter construction, medical and recreation industries (Kathiresan 2003). Many kinds of polyethylene are known, with most having the chemical formula $\left(\mathrm{C}_{2} \mathrm{H}_{4}\right)$ ${ }_{n} \mathrm{H}_{2}$. Thus, polyethylene is usually a mixture of similar organic compounds that differ in terms of the value of $n$ (www.wikepedia.org).

Plastic is advantageous as it is strong, light weight and durable. But, lack of degradability and the closing of landfill sites, as well as growing water and land pollution problems have led to concern about plastics. With the excessive use of plastics and increasing pressure being placed on capacities available for plastic waste disposal, the need for biodegradable plastics and biodegradation of plastic has assumed increasing importance in the last few years. Biodegradation is necessary for water-soluble or water-immiscible polymers, because they eventually enter water streams which can neither be recycled nor incinerated (Shah et al. 2008). The polyethylene is the most commonly found solid waste that has been recently recognized as a major threat to marine life. The polyethylene could sometimes cause blockage in intestine of fish birds and marine mammals (Spear et al. 1995; Seechi and Zarur 1999). The degradation of polyethylene can occur by different molecular mechanisms such as chemical, thermal, photo and biodegradation (Gu 2003). Thermal degradation of polymers is molecular deterioration as a result of overheating (Shah et al. 2008).

Biodegradability is evaluated by weight loss, tensile strength loss, changes in percent elongation and changes in polyethylene molecular weight distribution. Physicochemical distribution is initiated by treatment with acid at $70 \mathrm{C}$ and UV irradiation of the polyethylene film. These pre-treatment favors the microbial degradation of polyethylene.

The solid waste-related problems pose threat to mega cities. So, an attempt has been made in this paper to isolate the potent fungus from the soil of dumpsite area, which degrades polyethylene.

\section{Materials and methods}

\subsection{Collection of soil sample}

Soil sample was collected from a local dumpsite of Shivamogga district, brought to the laboratory and preserved under laboratory conditions for further use.

\subsection{Isolation and identification of fungi from soil}

Enrichment procedure was used for the isolation of fungus where polyethylene was used as sole source of carbon. Isolated fungus was identified based on its microscopic and macroscopic appearance using standard manuals (Ellis Ellis 1971, 1976; Pitt 1979; Domsch et al. 1980; Subramanian 1983; Ellis and Ellis 1997; Gilman 2001; Nagamani et al. 2006). The colonies were preserved at $4 \mathrm{C}$ in $2 \%$ agar slants of malt and yeast extract medium (Yamada-onodera et al. 2001). 


\section{Screening of fungi for polyethylene degradation}

\subsection{Plate assay}

The isolated fungus was inoculated into medium that contained $0.3 \mathrm{~g}$ of $\mathrm{NH}_{4} \mathrm{NO}_{3}, 0.5 \mathrm{~g}$ of $\mathrm{K}_{2} \mathrm{HPO}_{4} \cdot 0.1 \mathrm{~g}$ of NaCl, $0.02 \mathrm{~g}$ of $\mathrm{MgSO}_{4} \cdot 7 \mathrm{H}_{2} \mathrm{O}, 2 \mathrm{~g}$ of agar, $0.5 \mathrm{~g}$ of polyethylene and $100 \mathrm{ml}$ distilled water (Yamada-onodera et al. 2001). This agar plate test is also a simple semiquantitative method to know depolymerization of polymer by the organism. After inoculation with fungi into the medium containing fine particles of PE, the formation of a clear hallow around the colony indicates the first step of fungal biodegradation (Nishida and Tokiwa 1993).

\subsection{Degradation of polyethylene}

The pre-weighed disks of autoclaved, surface-sterilized and UV-treated polyethylene of $1 \mathrm{~cm}$ diameter prepared from polyethylene bags were aseptically transferred to the conical flask containing $50 \mathrm{ml}$ of mineral salt medium. Surface sterilization was done by treating polyethylene disks with ethanol for $1 \mathrm{~min}$, and then, they were treated with sodium hypochlorite solution for $3 \mathrm{~min}$ and were washed with sterile distilled water for three times. Loop full of organisms was added to medium. Control was maintained with polyethylene disks in the microbe-free medium. Triplicates were maintained for each type of polyethylene and left on shaker. After 3 months of incubation, the plastic disks were collected, washed thoroughly using distilled water, dried in hot air oven at $50 \mathrm{C}$ over night and then weighed for final weight (Kathiresan 2003).

\section{Confirmation of polyethylene degradation}

Polyethylene degradation was confirmed using scanning electron microscopy (SEM), Fourier transform infrared (FTIR) spectroscopy and nuclear magnetic resonance (NMR) spectroscopy (Shah et al. 2008).

\section{Screening of enzymes responsible for polyethylene degradation}

Earlier studies revealed that laccase and manganese peroxidase are responsible for polyethylene degradation. So, we carried out screening, mass production and crude extraction of these enzymes.

\subsection{Screening of laccase and manganese peroxidase enzyme}

The isolated fungus was screened for the laccase production using laccase screening medium (LSM). Fungus was inoculated in LSM agar plate, and the plate was incubated for 7 days in dark condition. The substrate utilized reddish brown color in screening medium indicated the positive strain for laccase (Viswanth et al. 2008). For manganese peroxidase, $\mathrm{H}_{2} \mathrm{O}_{2}$ was used to the same medium.

\subsection{Mass production by submerged fermentation}

The mass level production of the enzymes was carried out in mineral salt medium under suitable environmental conditions (Shradda et al. 2011). 


\subsection{Enzyme assay}

One milliliter of the culture supernatant was added with one $\mathrm{ml}$ of $2 \mathrm{mM}$ guaiacol and $3 \mathrm{ml}$ $10 \mathrm{mM}$ sodium acetate buffer $(\mathrm{pH} 4.6)$. The reaction mixture was incubated at $30 \mathrm{C}$ for $15 \mathrm{~min}$. The color change was measured using spectroscope at $450 \mathrm{~nm}$. One unit of laccase activity was defined as amount of enzyme required to hydrolyze guaiacol during incubation period. For the enzyme activity calculation of manganese peroxidase, same procedure was used but for the reaction mixture $1 \mathrm{ml}$ of $\mathrm{H}_{2} \mathrm{O}_{2}$ was added and incubated (Papinutti and Martinez 2006).

\subsection{Protein estimation}

Protein estimation was done to calculate specific activity of enzymes. The protein concentration was determined by the Lowry's method, as described by Lowry's et al. (1951) using bovine serum albumin (BSA) as a standard.

\subsection{Crude extraction of enzymes}

Culture filtrate was centrifuged, and supernatant was subjected for ammonium sulfate precipitation technique. Dialysis was carried out for crude extraction of enzymes (Shradda et al. 2011). The dialyzed samples were separated and characterized to determine molecular weight by sodium dodecyl sulfate polyacrylamide gel electrophoresis (SDSPAGE) and native PAGE.

5.6 To check capacity of extracted enzymes to degrade polyethylene

Crude enzymes that were extracted from precipitation and dialysis method were inoculated into sodium acetate buffer containing pre-weighed disks of polyethylene and incubated at room temperature for the period of 15 days on rotary shaker at $150 \mathrm{rpm}$. Enzymes were added to the flask every day to repeatedly treat the polyethylene membrane. Degradation of polyethylene was followed by weight loss and FTIR studies (Fujisawa et al. 2001).

\section{Results}

\subsection{Isolation and identification of fungi}

Penicillium simplicissimum was isolated and identified based on its morphological characters. P. simplicissimum was selected for study because of its predominant presence in soil contaminated with waste polyethylene plastic bags.

\subsection{Screening of fungi for polyethylene degradation}

\subsubsection{To check ability of fungi to grow on medium containing polyethylene}

The isolated fungus was able to grow on agar medium containing polyethylene as sole carbon source. This showed its capacity to utilize polyethylene as carbon source and its capacity to degrade polyethylene. 


\subsubsection{Degradation of autoclaved polyethylene}

Penicillium simplicissimum was able to degrade autoclaved polyethylene, indicating its capacity to use polyethylene as sole carbon source. The weight loss for autoclaved polyethylene was $16 \%$ (Table 1).

\subsubsection{Degradation of UV-treated polyethylene}

Penicillium simplicissimum was able to degrade UV-treated polyethylene more efficiently than autoclaved and surface sterilized. The weight loss for UV-treated polyethylene was $38 \%$ (Table 2). Degradation was more here because of pre-treatment using UV light and acid. UV light is known as initiator of polyethylene oxidation and enhances the fungal degradation, when compared with its corresponding UV-untreated control (Lee et al. 1991). Both UV and acid treatments cause pro-oxidant and photooxidant to produce free radicals on the long chain, causing the material to lose some of its physical properties to become oxidized and more accessible to microbial biodegradation (Cornell et al. 1984). The fungal attachment was found on the surface of the plastic, and it indicates possible utilization of plastic as carbon source. Acid and UV treatments improve polyethylene hydrophilic level and reduce its polymer chain length by oxidation for easy accessible of polyethylene for microbial degradation (Bikiaris et al. 1999).

\subsubsection{Degradation of surface-sterilized polyethylene}

Penicillium simplicissimum was able to degrade surface-sterilized polyethylene. This method confirmed that this organism can utilize polyethylene without any pre-treatment such as heat, UV light and acid. The weight loss for surface-sterilized polyethylene was $7.7 \%$ (Table 3). Weight losses of all types of polyethylene are shown in following figure (Fig. 1).

Table 1 Weight loss of autoclaved polyethylene

\begin{tabular}{lllll}
\hline Sl. no. & Initial weight & Final weight $(\mathrm{mg})^{\mathrm{a}}$ & Weight loss $(\mathrm{mg})$ & Weight loss $(\%)$ \\
\hline 1. & 0.10 & 0.084 & $0.016 \pm 0.001$ & 16 \\
\hline
\end{tabular}

\pm Standard deviation

a Mean

Table 2 Weight loss of UV-treated polyethylene

\begin{tabular}{lllll}
\hline Sl. no. & Initial weight & Final weight $(\mathrm{mg})^{\mathrm{a}}$ & Weight loss $(\mathrm{mg})$ & Weight loss $(\%)$ \\
\hline 1. & 0.10 & 0.062 & $0.038 \pm 0.001$ & 38 \\
\hline
\end{tabular}

\pm Standard deviation

a Mean 
Table 3 Weight loss of surface-sterilized polyethylene

\begin{tabular}{lllll}
\hline Sl. no. & Initial weight & Final weight $(\mathrm{mg})^{*}$ & Weight loss $(\mathrm{mg})$ & Weight loss $(\%)$ \\
\hline 1. & 0.10 & 0.0923 & $0.0077 \pm 0.0014$ & 7.7 \\
\hline
\end{tabular}

\pm Standard deviation

a Mean

\subsection{Confirmation of polyethylene degradation}

\subsubsection{Observation of disks using SEM}

Scanning electron microscopy photograph of autoclaved polyethylene showed disruption of its structure (Fig. 2). UV-treated polyethylene showed formation of holes and some cracks on polyethylene structure. Disruption of UV-treated polyethylene structure was more compared to autoclaved and UV-treated polyethylene, because of its pretreatment with UV light and acid (Fig. 3). SEM photograph of surface-sterilized polyethylene showed little changes in its structure compared to autoclaved and UV-treated polyethylene (Fig. 3). SEM photograph of control polyethylene did not any change in its structure (Fig. 2). Changes in microbial-treated polyethylene confirmed degradation capacity of $P$. simplicissimum.

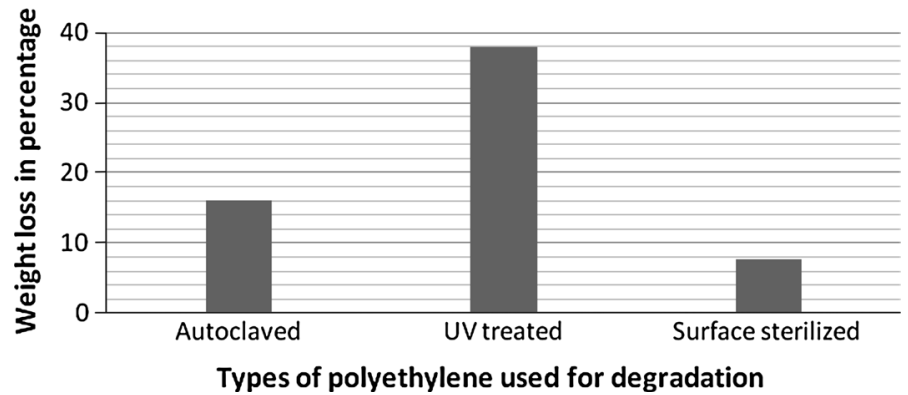

Fig. 1 Weight loss of different types of polyethylene
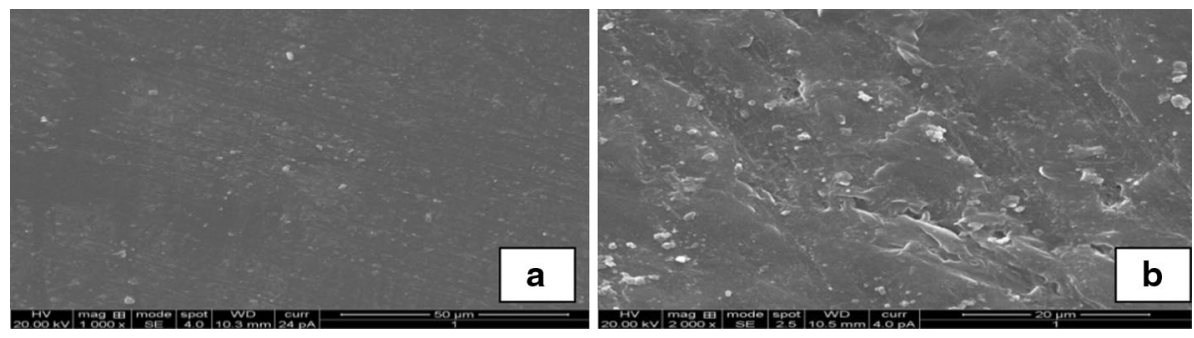

Fig. 2 SEM photographs of control (a) and autoclaved polyethylene (b) 

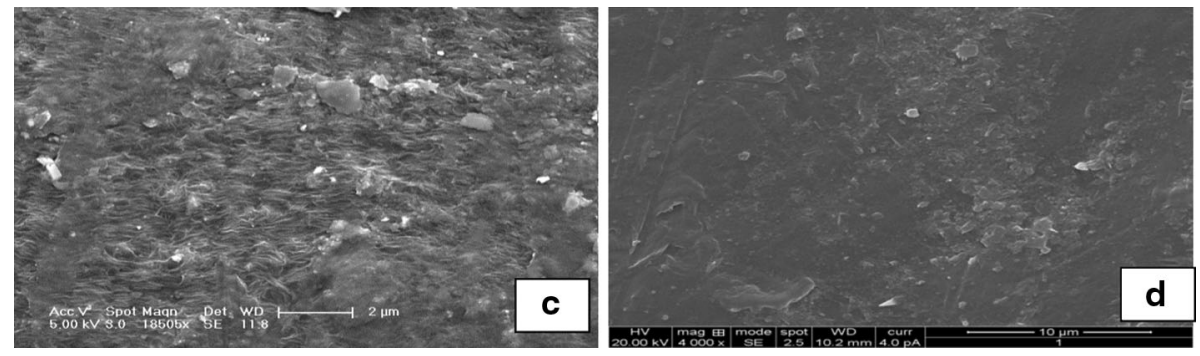

Fig. 3 SEM photographs of UV-treated (c) and surface-sterilized polyethylene (d)

\subsubsection{Observation of disks using FTIR}

Fourier transform infrared results confirmed polyethylene degradation. Following are the figures showing FTIR spectrum of control, autoclaved, UV-treated and surface-sterilized polyethylene. FTIR results were analyzed using standard chart available.

In control, polyethylene degradation products were absent. In autoclaved polyethylene, carboxylic acids $\left(3,300-2,500 \mathrm{~cm}^{-1}\right)$, aldehydes $\left(2,920,43 \mathrm{~cm}^{-1}\right)$ and alcohol, esters and ether $\left(1,249,28 \mathrm{~cm}^{-1}\right)$ groups were released indicating degradation (Fig. 4).

UV-treated polyethylene showed formation of carboxylic acids $\left(3,194,39 \mathrm{~cm}^{-1}\right)$, aldehydes $\left(2,717,70 \mathrm{~cm}^{-1}\right)$, alcohols, esters and ethers $\left(1,298,59 \mathrm{~cm}^{-1}\right)$ and aromatic $\left(893,13 \mathrm{~cm}^{-1}\right)$ groups were released. In surface-sterilized polyethylene, alcohols, phenols $\left(3,369,98 \mathrm{~cm}^{-1}\right)$, carboxylic acids $\left(2,635,03 \mathrm{~cm}^{-1}\right)$, aromatics $\left(1,500-1,400 \mathrm{~cm}^{-1}\right)$ and ester and ether $\left(1,018,43 \mathrm{~cm}^{-1}\right)$ groups were released (Fig. 5). Formation of aldehydes, esters, phenols and carboxylic acids confirmed degradation of polyethylene by the isolated fungus.

\subsubsection{Observation of disks using NMR spectroscopy}

Aromatic protons were released on polyethylene structure indicating its degradation. Aromatic protons were not present in control polyethylene (Fig. 6).

6.4 Screening and characterization of polyethylene-degrading enzymes

Penicillium simplicissimum showed positive result for both laccase and manganese peroxidase enzyme.

\subsubsection{Mass production of enzymes}

Laccase and manganese peroxidase enzymes were produced in large amount using submerged fermentation.

\subsubsection{Enzyme assay}

Activity of manganese peroxidase $(0.0 .00896 \mathrm{IU} / \mathrm{ml})$ was more compared to laccase activity (0.00888 IU/ml) (Table 4; Fig. 7). 


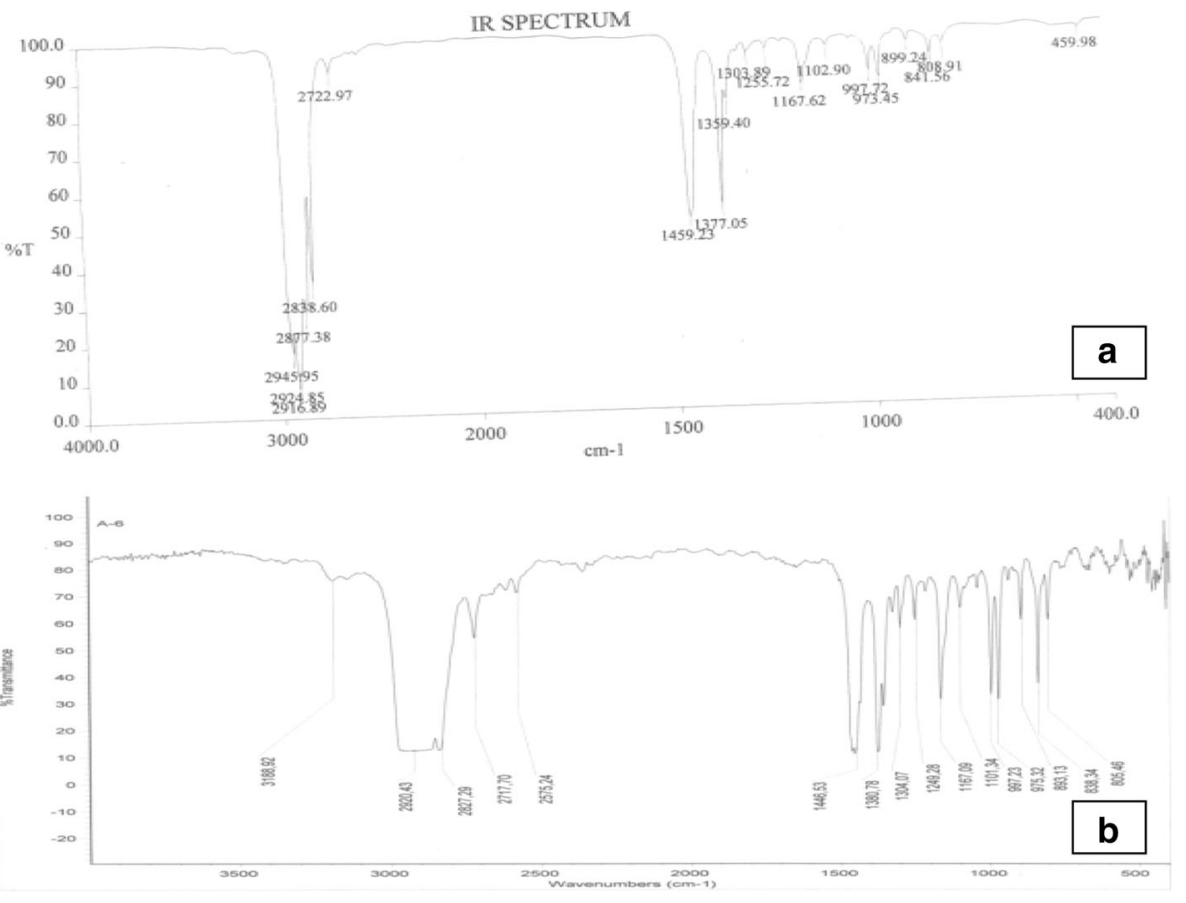

Fig. 4 FTIR spectrum of control (a) and autoclaved polyethylene (b)

\subsubsection{Protein estimation}

Protein estimation was done to calculate specific activity of enzymes. Specific activity was calculated to know the rate of reaction of an enzyme. Specific activity of manganese peroxidase $(0.0389 \mu \mathrm{mol} / \mathrm{ml} / \mathrm{mg} / \mathrm{min})$ was more compared to laccase $(0.035 \mu \mathrm{mol} / \mathrm{ml} / \mathrm{mg} / \mathrm{min})$.

\subsubsection{Crude extraction of enzyme}

SDS-PAGE and native PAGE were carried out to determine molecular weight of laccase and manganese peroxidase enzyme. Molecular weight of laccase was $66 \mathrm{kDa}$ and that of manganese peroxidase was $60 \mathrm{kDa}$ (Fig. 8, Fig. 9).

\subsubsection{Testing of polyethylene-degrading ability of crude enzymes}

Both enzymes when treated with polyethylene disk showed weight loss (Table 6; Fig. 10) and morphological changes in FTIR spectrum.

Fourier transform infrared spectrum of polyethylene treated with laccase and manganese peroxidase showed formation of carboxylic acids, aldehydes, aromatics, alcohols, esters, ethers and alkyl halides groups indicating degradation capacity of laccase and manganese peroxidase (Fig. 11). 

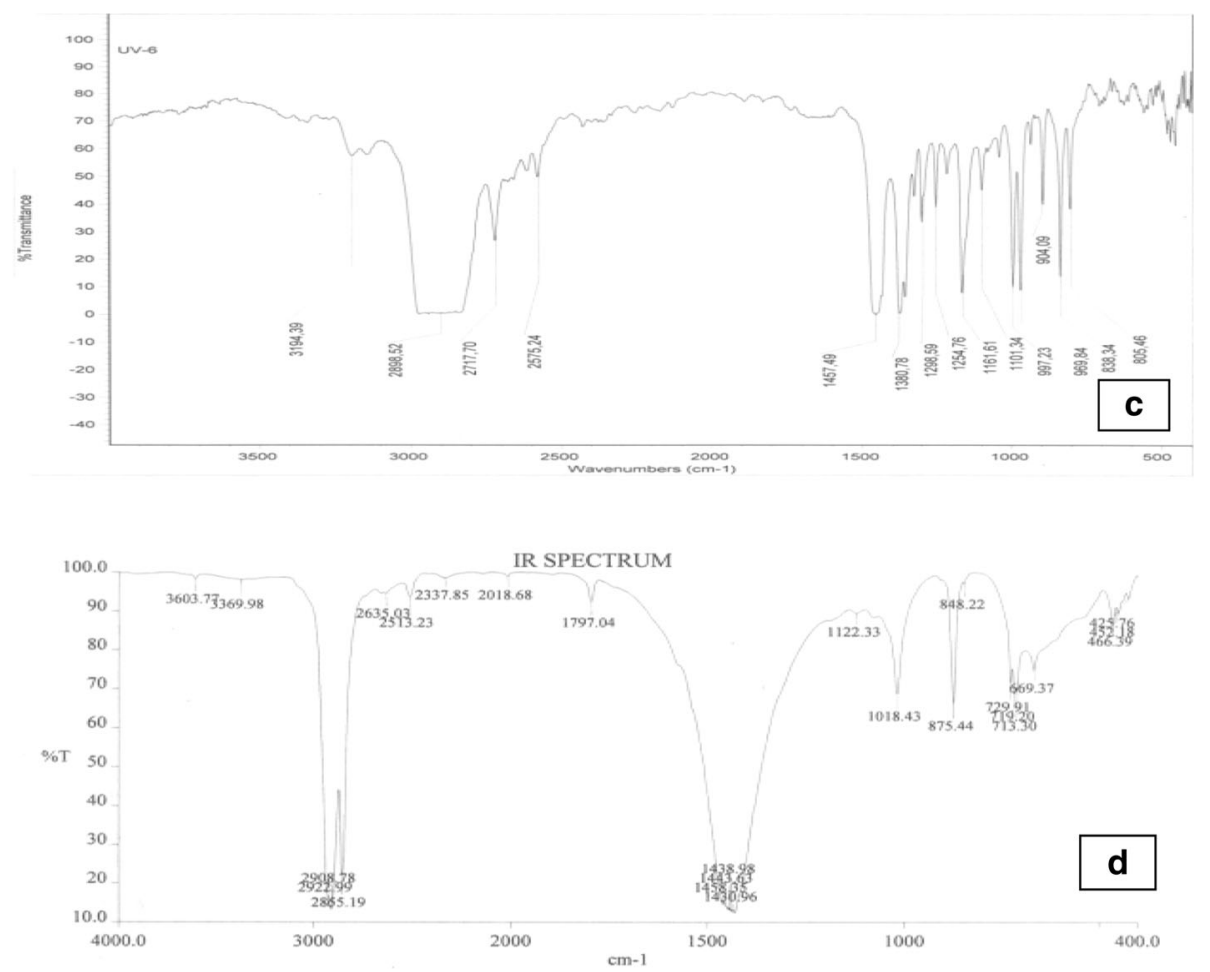

Fig. 5 FTIR spectrum of UV-treated (c) and surface-sterilized polyethylene (d)

\section{Discussion}

Penicillium simplicissimum was isolated from local dumpsite of Shivamogga district. After the growth of fungus on polyethylene-containing medium, it was screened for degradation of autoclaved, UV-treated and surface-sterilized polyethylene. $P$. simplicissimum was able to degrade UV-treated (38\%) polyethylene more efficiently than autoclaved $(16 \%)$ and surface sterilized $(7.7 \%)$. After the treatment of polyethylene with UV light, P. simplicissimum was able to degrade it more efficiently. Same results were concluded by Albertsson et al. (1987) concluded that carbonyl groups are produced by UV light or oxidizing agents and these groups are the main factors at the beginning of the degradation, being attacked by microorganisms that degrade the shorter segments of polyethylene chains.

Singh et al. (2012) carried out degradation of LDPE using Aspergillus fumigatus and Penicillium sp. According to their work, A. fumigatus was able to degrade $4.65 \%$ of polyethylene and Penicillium sp. degraded $6.58 \%$ of polyethylene.

Mahalakshmi et al. (2012) studied degradation of polyethylene using microorganisms isolated from compost soil. But, in our work, polyethylene-degrading microorganisms were isolated from dumpsite soil. They studied degradation by inoculating isolated organisms into mineral salt medium containing 1 gram of polyethylene films as sole carbon source. Degradation was studied using SEM and FTIR. SEM studies showed formation of cavities and erosion. They analyzed degraded products by gas chromatography. Degraded products 


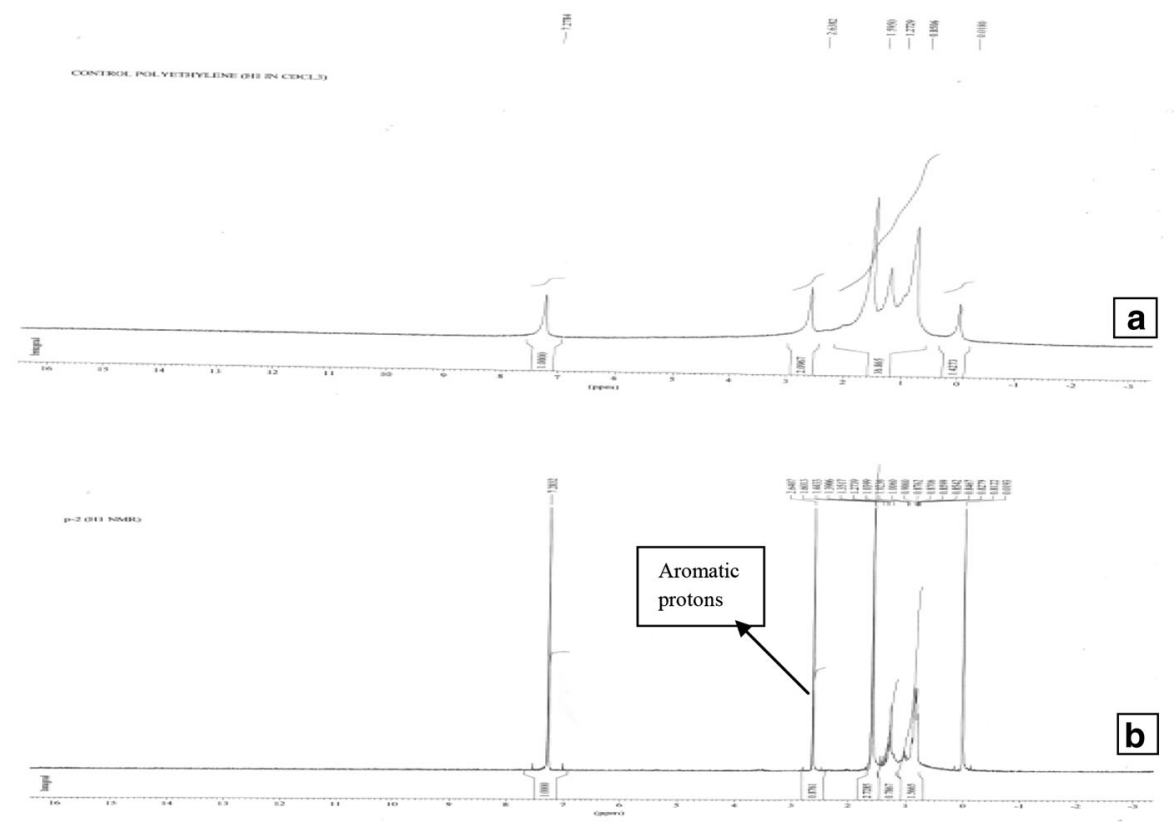

Fig. 6 NMR spectra of control (a) and treated polyethylene (b)

were not analyzed in our work. SEM and FTIR were also used in our study to evaluate biodegradation. In our work also, polyethylene treated with $P$. simplicissimum showed formation of cavities and erosions.

Pramila and Ramesh (2011) studied the biodegradation of low-density polyethylene by two fungal strains isolated from municipal landfill area. The degrading ability of the two fungal strains was evaluated by performing colonization studies, SEM and Sturm test analysis. Colonization studies on LDPE film were performed over a period of 1 month by measuring the fresh weight of the fungus. LDPE films colonized by fungus were analyzed by SEM for any structural changes caused in the LDPE films. LDPE degradation by the fungal strains was further evaluated by measuring the $\mathrm{CO}_{2}$ evolved which was calculated gravimetrically and volumetrically by Sturm test. Fungi were identified as Mucor circinilloides and A. flavus. Even in our work, we have evaluated degradation using SEM.

Nwogu et al. (2012) studied degradation of polyethylene using mushrooms, and degradation was confirmed by FTIR studies. FTIR analysis showed additional absorbance at regions corresponding to carbonyl groups in the spectra of polyethylene biodegraded by $P$. tuber-regium and $P$. pulmonarius, suggesting that polyethylene was degraded oxidatively.

Kuroki et al. (1982) reported mechanism to detect long-chain branching in the thermal degradation of linear-high-density polyethylene. They have established a quantitative method for determining the number of double bonds (terminal vinyl, trans-vinylene and vinylidene groups), terminal methyl groups and LCB by ' $\mathrm{H}$ and 13C NMR spectroscopies. We have used NMR to detect degradation capacity of $P$. simplicissimum. Aromatic protons were formed in treated polyethylene and were absent in control.

Shimao (2001) studied degradation of high molecular weight polyethylene with partially purified manganese peroxidase from Phanerochaete chrysosporium. They carried out this experiment under nitrogen-limited and carbon-limited conditions. Even in our 
Table 4 Enzyme activity of laccase and manganese peroxidase

\begin{tabular}{llllllllll}
\hline $\begin{array}{l}\text { Enzyme/ } \\
\text { weeks }\end{array}$ & 4 & 5 & 6 & 7 & 8 & 9 & 10 & 11 & 12 \\
\hline Laccase & 0.00078 & 0.00113 & 0.00124 & 0.00287 & 0.00509 & 0.00679 & 0.00888 & 0.00549 & 0.00379 \\
$\begin{array}{c}\text { Manganese } \\
\text { peroxidase }\end{array}$ & 0.00084 & 0.00120 & 0.00133 & 0.00294 & 0.00515 & 0.00685 & 0.00896 & 0.00553 & 0.00384 \\
\hline
\end{tabular}

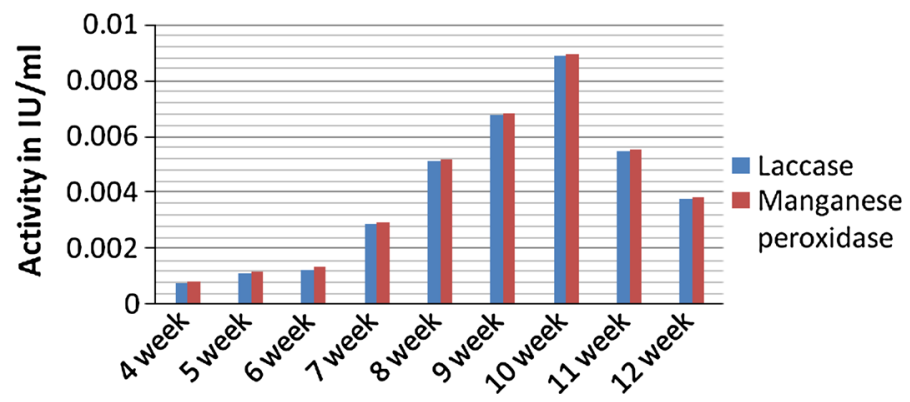

Fig. 7 Enzyme activity of laccase and manganese peroxidase

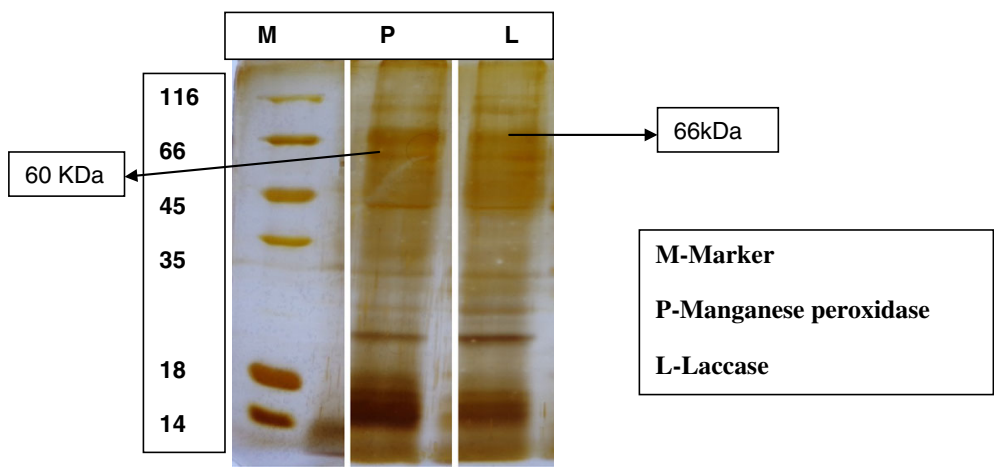

Fig. 8 Molecular weight of laccase and manganese peroxidase in SDS-PAGE

experiment, we carried out degradation of polyethylene with partially purified manganese peroxidase enzyme from $P$. simplicissimum. Weight loss and FTIR results confirmed polyethylene degradation by this partially purified enzyme.

Iiyoshi et al. (1998) carried out degradation of polyethylene in the presence of Tween $80, \mathrm{Mn}(\mathrm{II})$ and $\mathrm{Mn}(\mathrm{III})$ chelator. They confirmed that manganese peroxidase is a key enzyme in biodegradation of polyethylene. Among laccase and manganese peroxidase purified from $P$. simplicissimum, manganese peroxidase showed maximum degradation indicating its main role in polyethylene degradation.

Fujisiawa et al. (2001) investigated the role of laccase-mediator system for biodegradation of polyethylene in the presence of 1-hydroxybenzotriazole (HBT). They used 


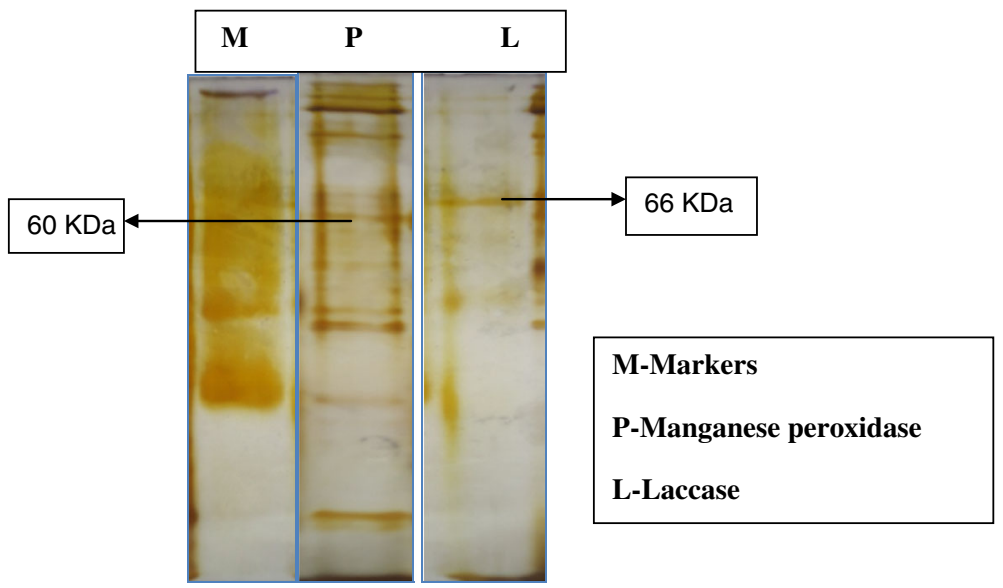

Fig. 9 Molecular weight of laccase and manganese peroxidase in native PAGE

Table 6 Weight loss of enzyme-treated polyethylene

\begin{tabular}{llllll}
\hline S1. no. & $\begin{array}{l}\text { Name of the } \\
\text { enzymes }\end{array}$ & $\begin{array}{l}\text { Initial weight } \\
(\mathrm{mg})\end{array}$ & $\begin{array}{l}\text { Final weight } \\
(\mathrm{mg})\end{array}$ & Weight loss (mg) & $\begin{array}{l}\text { Weight loss } \\
(\%)\end{array}$ \\
\hline 1 & Laccase & 0.1 & 0.0997 & $0.0003 \pm 0.0001$ & 0.3 \\
2 & $\begin{array}{l}\text { Manganese } \\
\text { peroxidase }\end{array}$ & 0.1 & 0.0996 & $0.0004 \pm 0.0002$ & 0.4 \\
\hline
\end{tabular}

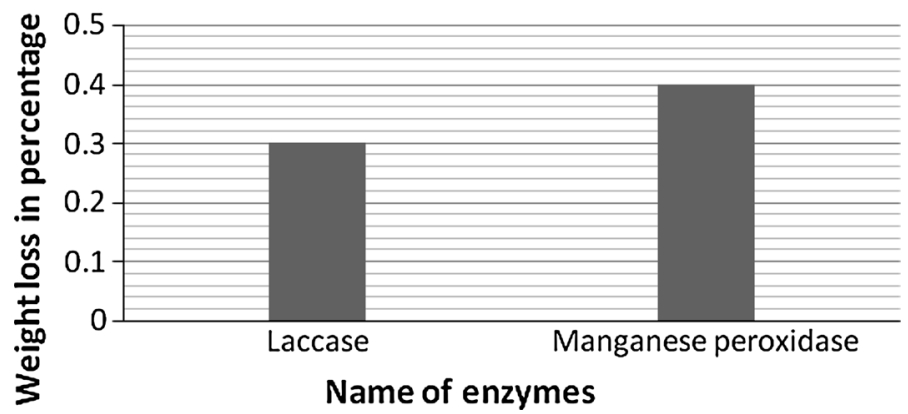

Fig. 10 Weight loss of enzyme-treated polyethylene

laccase of Trametes versicolor. Degradation of polyethylene was confirmed by changes in relative elongation, relative tensile strength and molecular weight distribution. All these results confirmed degradation of polyethylene by laccase-mediator system. We carried out degradation of polyethylene with partially purified laccase. Weight loss and FTIR results confirmed degradation of polyethylene by laccase.

According to earlier literature available, molecular weight of laccase is around 60-90 kDa (Shradda et al. 2011) and molecular weight of manganese peroxidase is around 

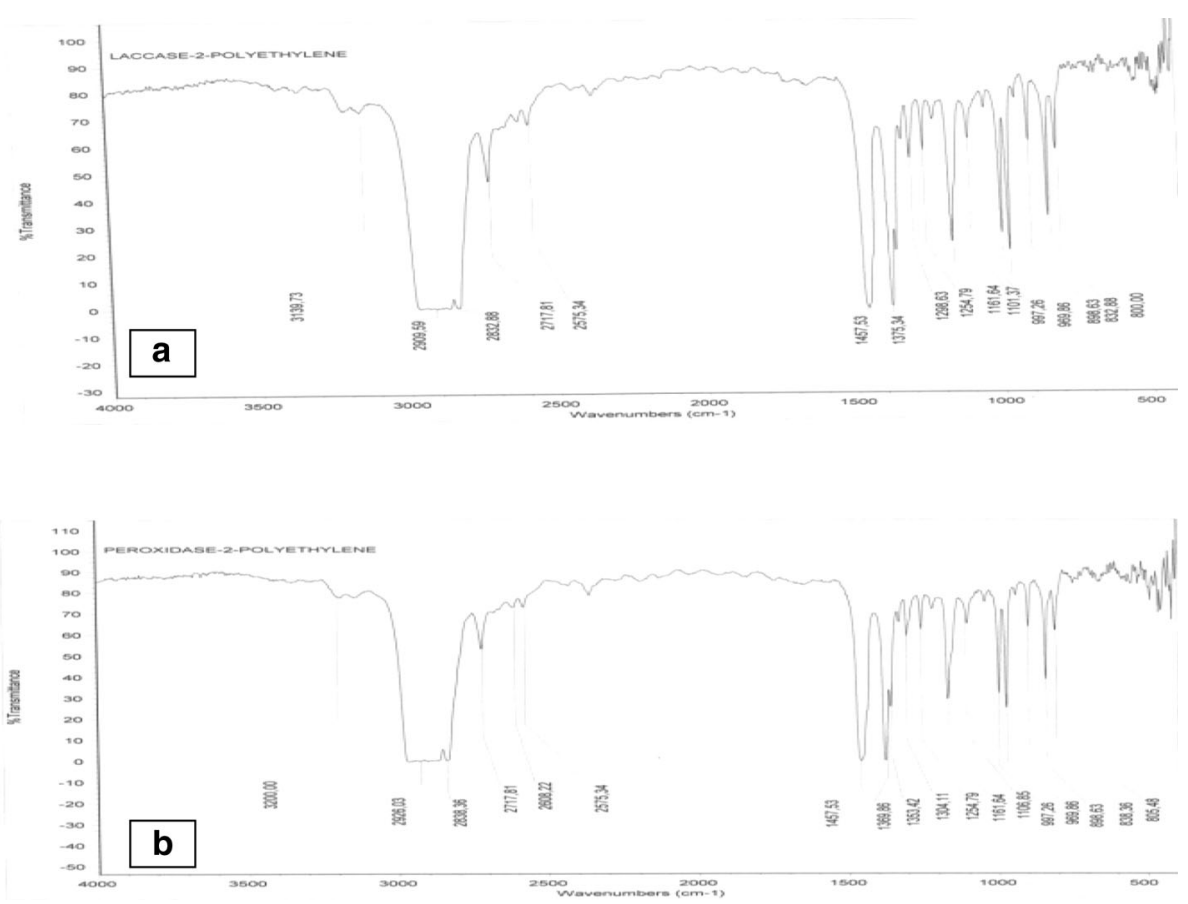

Fig. 11 FTIR spectrum of laccase- and manganese peroxidase-treated polyethylene

40-48 kDa (Leonowicz et al. 2001). In our work, molecular weight of laccase was around $66 \mathrm{kDa}$ and molecular weight of manganese peroxidase was around $60 \mathrm{kDa}$.

\section{Conclusion}

Degradation of polyethylene was carried out with $P$. simplicissimum which was isolated from dumpsite soil. $P$. simplicissimum was able to degrade polyethylene. Efficiency of $P$. simplicissimum to use UV-treated polyethylene as sole source of carbon was much better than autoclaved and surface sterilized. Degradation was monitored by weight loss, SEM, FTIR and NMR studies. Weight loss of UV-treated polyethylene (38\%) was more followed by autoclaved (16\%) and surface sterilized (7.7 \%). FTIR results showed formation of aldehyde, alcohol, carboxylic acid, aromatic and ether group formation indicating degradation of polyethylene by $P$. simplicissimum. NMR results showed formation of aromatic protons and $\mathrm{CH}=\mathrm{CH}$ protons, and these groups were absent in control polyethylene. All these results confirmed polyethylene degradation. Enzymes responsible for polyethylene degradation were identified as laccase and manganese peroxidase. These enzymes were partially purified from isolated fungus, and molecular weight of laccase was around $66 \mathrm{kDa}$ and that of manganese peroxidase was around $60 \mathrm{kDa}$. Efficiency of partially purified enzymes to degrade polyethylene was evaluated by inoculating them in sodium acetate buffer containing pre-weighed polyethylene disks. Weight loss and FTIR results confirmed polyethylene degradation by these enzymes. Efficiency of manganese peroxidase $(0.6 \%)$ was more than that of laccase $(0.5 \%)$. By observing all these results, 
we can confirm that $P$. simplicissimum can act as better solution for disposal of polyethylene. Enzymes extracted from this fungus can also be used for biodegradation of polyethylene. In future, work can be done on optimization of conditions, such as water activity and $\mathrm{pH}$, for maximum polyethylene degradation.

Acknowledgments This work was carried out with the help of financial support provided by Rajiv Gandhi Fellowship, UGC New Delhi. Author is also grateful to Chairman, Department of Microbiology, Kuvempu University, Shankaraghatta, for giving a good support and laboratory facility for this research work.

\section{References}

Albertsson, A. C., Andersson, S. O., \& Karlsson, S. (1987). The mechanism of biodegradation of polyethylene. Polymer Degradation and Stability, 18, 73-87.

Bikiaris, D., Aburto, J., Alric, I., Borredon, E., Botey, M., \& Betchev, C. (1999). Mechanical properties and biodegradability of LDPE blends with fatty-acid esters of amylase and starch. Journal of Applied Polymer Science, 71, 1089-1100.

Cornell, J. H., Kaplan, A. M., \& Rogers, M. R. (1984). Biodegradation of photooxidized polyalkalynes. Journal of Applied Polymer Science, 29, 2581-2597.

Domsch, K. H., Gams, W., \& Anderson, T. H. (1980). Compendium of soil fungi (pp. 1-859). New York: Academic Press Inc.

Ellis, M. B. (1971). Dematiaceous hyphomycetes. England: Kew: Common wealth mycological institute.

Ellis, M. B. (1976). More dematiaceous hyphomycetes (pp. 1-507). England: Kew: Common wealth mycological institute.

Ellis, M. B., \& Ellis, J. P. (1997). Microfungi on land plants: An identification handbook (p. 868). London: Croom Helm: Richmond Publishers.

Fujisawa, H., Hirai, H., \& Nishida, T. (2001). Degradation of Polyethylene and Nylon-66 by laccase mediator system. Journal of Polymer and Environment, 9, 103-108.

Gilman, J. C. (2001). A manual of soil fungi (2nd ed., pp. 1-392). New Delhi: Biotech Books.

Gu, J. D. (2003). Microbiological deterioration and degradation of synthetic polymeric materials: Recent research advances. International Biodeterioration and Biodegradation, 52, 69-91.

Iiyoshi, Y., Tsutsumi, Y., \& Nishida, T., (1998). Polyethylene degradation by lignin degrading fungi and manganese peroxidase. Journal of Wood Science, 44, 222-229.

Kathiresan, K. (2003). Polyethylene and plastic degrading microbes from the mangrove soil. Revista de Biologia Tropical, 51, 629-634.

Kuroki, T., Sawaguchi, T., Niikuni, S., \& Ikemura, T. (1982). Mechanism for long-chain branching in the thermal degradation of linear high-density polyethylene. Macromolecules, 15, 1460-1464.

Lee, B., Pometto, A. L., Fratzke, A., \& Bailery, T. B. (1991). Biodegradation of degradable plastic polyethylene by Phanerochaete and Streptomyces species. Applied and Environmental Microbiology, 57, 678-685.

Leonowicz, A., Cho, N. S., Luterek, J., Wilkolazka, A., Wasilewska, M. W., Matuszewska, A., et al. (2001). Fungal laccase: Properties and activity on lignin. Journal of Basic Microbiology, 41, 185-227.

Lowry, O. H., Rosebrough, N. J., Farr, A. L., \& Randall, R. J. (1951). Protein measurement with the Folin phenol reagent. Journal of General Microbiology, 31, 3017-3027.

Mahalakshmi, V., Siddiq, A., \& Andrew, S. N. (2012). Analysis of polyethylene degrading microorganisms isolated from compost soil. International Journal of Pharmaceutical and Biological Archives, 3, $1190-1196$.

Nagamani, A., Kunwar, I. K., \& Manoharachary, C. (2006). Hand book of soil fungi. New Delhi: I. K. International Pvt. Ltd.

Nishida, H., \& Tokiwa, Y. (1993). Distribution of poly ( $\beta$ - Hydroxybutyrate) and poly ( $€$ - caprolactone) aerobic degrading microorganisms in different environments. Journal of Environmental Polymer Degradation, 1, 227-233.

Nwogu, N. A., Atuanaya, E. I., and Akpaja, E. O. (2012). Capability of selected mushrooms to biodegrade polyethylene. Mycosphere Doi, 455-462.

Papinutti, L., \& Martinez, J. M. (2006). Production and characterization of laccase and manganese peroxidase from the ligninolytic fungus Fomes sclerodermeus. Journal of Technology and Biotechnology, $81,1064-1070$. 
Pitt, J. I. (1979). The genus Penicillium and its teleomorphic states Eupenicillium and Talaromyces (pp. 1-634). London: Academic Press Inc, Ltd.

Pramila, R. \& Ramesh, K. V. (2011). Biodegradation of low density polyethylene by fungi isolated from municipal landfill area. Journal of Microbiology and Biotechnology Research, 1, 131-136.

Seechi, E. R., \& Zarur, S. (1999). Plastic debris ingested by a Blainville's beaked whale, Mesoplodon densirostris. Washed ashore in Brazil. Aquatic Mammal, 25, 21-24.

Shah, A. A., Hasan, F., Hameed, A., \& Ahmed, S. (2008). Biological degradation of plastics: A comprehensive review. Biotechnology Advances, 26, 246-265.

Shimao, M. (2001). Biodegradation of plastics. Current Opinion Biotechnology, 12, 242-247.

Shraddha, Shekher, R., Sehgal, S., Kamtania, M., and Kumar, A. (2011). Laccase microbial source production, purification, potential biotechnological application, Enzyme Research, 1-11.

Singh, V., Dubey, M. \& Bhadauria, S. (2012). Microbial degradation of polyethylene (low density) by Aspergillus fumigatus and Penicillium sp. Asian Journal of Experimental Biology and Science, 34, 98-501.

Spear, L. B., Ainely, D. G., \& Ribie, C. A. (1995). Incidence of plastic in seabirds from the tropical Pacific 1984-91: Relation with distribution of species, sex, age, season, year and body weight. Marine Environment Research, 40, 123-141.

Subramanian, C. V. (1983). Hyphomycetes, taxonomy and biology (pp. 410-461). London: New York: Academic Press.

Viswanath, B., Chandra, M. S., Pallavi, H., \& Reddy, B. R. (2008). Screening and assessment of laccase producing from different environmental samples. African Journal of Biotechnology, 7, 1129-1133.

www.wikepedia.org.

Yamada-onodera, K., Mukumoto, H., Katsuyaya, Y., Saiganji, A., \& Tani, Y. (2001). Degradation of polyethylene by a fungus Penicillium simplicissium YK. Polymer Degradation and Stability, 72, 323-327. 